\title{
A smart nanofibrous material for adsorbing and detecting elemental mercury in air
}

\author{
Antonella Macagnano ${ }^{1}$, Viviana Perri ${ }^{1,2}$, Emiliano Zampetti $^{1}$, Andrea Bearzotti ${ }^{1}$, Fabrizio De Cesare ${ }^{1,3}$, \\ Francesca Sprovieri ${ }^{4}$, and Nicola Pirrone ${ }^{1}$ \\ ${ }^{1}$ Institute of Atmospheric Pollution Research-CNR, Via Salaria km 29300, 00016 Montelibretti (RM), Italy \\ ${ }^{2}$ University of Calabria, Via Pietro Bucci, 87036 Arcavacata di Rende (CS), Italy \\ ${ }^{3}$ DIBAF-University of Tuscia, Via San Camillo de Lellis, 01100 Viterbo, Italy \\ ${ }^{4}$ Institute of Atmospheric Pollution Research-CNR, Division of Rende, c/o UNICAL-Polifunzionale, 87036 Arcavacata di \\ Rende (CS), Italy
}

Correspondence to: Antonella Macagnano (a.macagnano@iia.cnr.it, antonella.macagnano@cnr.it)

Received: 30 November 2016 - Discussion started: 16 December 2016

Revised: 27 March 2017 - Accepted: 26 April 2017 - Published: 13 June 2017

\begin{abstract}
The combination of the affinity of gold for mercury and nanosized frameworks has allowed for the design and fabrication of novel kinds of sensors with promising sensing features for environmental applications. Specifically, conductive sensors based on composite nanofibrous electrospun layers of titania easily decorated with gold nanoparticles were developed to obtain nanostructured hybrid materials capable of entrapping and revealing gaseous elemental mercury (GEM) traces from the environment. The electrical properties of the resulting chemosensors were measured. A few minutes of air sampling were sufficient to detect the concentration of mercury in the air, ranging between 20 and $100 \mathrm{ppb}$, without using traps or gas carriers (LOD: $1.5 \mathrm{ppb})$. Longer measurements allowed the sensor to detect lower concentrations of GEM. The resulting chemosensors are expected to be low cost and very stable (due to the peculiar structure), requiring low power, low maintenance, and simple equipment.
\end{abstract}

\section{Introduction}

Mercury $(\mathrm{Hg})$ is released into the atmosphere through human activities, predominantly fossil fuel combustion, and naturally, for example, from soil outgassing, volcanoes, and evasion from the sea (Pirrone et al., 2010; Pacyna et al., 2010). One of the more troublesome issues in recent years has been to quantify not only the strength of emission sources but also the effects of the re-emission of previously deposited $\mathrm{Hg}$ on the overall distribution, concentration, and speciation of $\mathrm{Hg}$ in the atmosphere (Hedgecock et al., 2003). The deposition of atmospheric $\mathrm{Hg}$ depends on its chemical speciation, where the term speciation is used to distinguish between the gaseous elemental (GEM) and gaseous oxidized forms of $\mathrm{Hg}$ (gaseous oxidized mercury, GOM; particle-bound mercury, PBM) and their chemical and physical characteristics (Lyman et al., 2010; Sprovieri et al., 2016, 2017). To be precise, total gaseous mercury (TGM) is mainly comprised of GEM with minor fractions of other volatile species (e.g., $\mathrm{HgO}, \mathrm{HgCl}_{2}, \mathrm{HgBr}_{2}, \mathrm{CH}_{3} \mathrm{HgCl}$, or $\left.\left(\mathrm{CH}_{3}\right)_{2} \mathrm{Hg}\right)$. However, in spite of the conceptual differences between TGM and GEM, they have often been used without clear distinction. This was allowable to a degree as the predominant fraction of TGM (usually in excess of $99 \%$ ) is often represented by GEM under normal conditions. GEM is relatively inert under atmospheric conditions, only slightly soluble, and quite volatile, whereas several oxidized $\mathrm{Hg}$ forms found in the atmosphere are both soluble and involatile; thus they are efficiently scavenged and consequently deposited by liquid atmospheric water, such as rain and fog droplets, but also deliquesced aerosol particles. The dispersion of GEM on a global scale therefore depends on the rate of its oxidation in the atmosphere as this determines its long atmospheric lifetime (generally $>1$ year), limiting local emission controls in protecting all environments. Several international initiatives and programs (i.e., the United Nations Environment Programme; UNEP) 
have also made a tremendous effort to identify and quantify $\mathrm{Hg}$ pollution across the globe, especially the "hot-spots", to reduce the risk of exposure to this neurotoxic pollutant. Policy makers are working toward a worldwide effort to support the construction of an accurate global $\mathrm{Hg}$ budget and to model the benefits or consequences of changes in $\mathrm{Hg}$ emissions, for example, as proscribed by the Minamata Convention. Anticipating a global policy, in 2010 the European Commission began a 5-year project called the Global Mercury Observation System (GMOS; www.gmos.eu) to create a coordinated global network to fill the gaps in emission monitoring and in the spatial coverage of environmental observations, mostly in the tropical regions and the Southern Hemisphere, thus adequately improving models and making policy recommendations (Sprovieri et al., 2016, 2017). To date, the GMOS network consists of more than 43 monitoring stations worldwide, including high-altitude and sea-level monitoring sites located in climatically diverse regions, including the polar areas (Sprovieri et al., 2016, 2017). One of the major outcomes of GMOS has been an interoperable e-infrastructure developed following the Group on Earth Observations (GEO) data sharing and interoperability principles, which allows us to provide support to UNEP for the implementation of the Minamata Convention (i.e., Article 22). GMOS activities are currently part of the GEO strategic plan (2016-2025) within the flagship project to track persistent pollutants. The overall goal of this flagship project is to support the development of GEOSS (Global Earth Observation System of Systems) by fostering research and technological development on new advanced sensors for in situ and satellite platforms in order to lower the management costs of long-term monitoring programs and improve the spatial coverage of observations. Since automated measurement methods for $\mathrm{Hg}$ often require power, carrier gases like argon, and significant operator training, they are difficult to apply for understanding $\mathrm{Hg}$ air concentrations and deposition across broad regional and global scales. Therefore, the lack of an inexpensive, stand-alone, low-power, and low-maintenance sensor is a primary technical issue to be solved for the sustainability of a global network such as GMOS. Previous research has highlighted the fact that $\mathrm{Hg}$ concentration levels in air vary greatly across different environmental locations; these include remote polar regions, background or rural, and urban locations with an average range between $1.5 \mathrm{ngm}^{-3}$ (GEM) and $1 \mathrm{pgm}^{-3}$ (GOM and PBM) depending on the speciation. Hence, for the determination of atmospheric $\mathrm{Hg}$ at such low levels, sampling and analytical methods should be sensitive enough to quantify the concentration profiles of diverse $\mathrm{Hg}$ species in each respective environmental setting to better understand their environmental behavior and patterns. Fortunately, many advances in analytical methodologies have made it possible to study atmospheric $\mathrm{Hg}$ in different environmental locations. However, several limitations and difficulties are still experienced in $\mathrm{Hg}$ analysis, as most methods cannot yet directly or accurately determine minor
Hg species (Gustin et al., 2013). Hence, efforts should be continued to further secure the reliability, traceability, and accuracy of $\mathrm{Hg}$ levels measured in air. Current air-monitoring devices are amply sensitive to detect the global background but are costly and high maintenance with complicated configurations and electricity requirements. A further limitation is the ultralow levels of ambient mercury in the atmosphere. The typical background gaseous elemental mercury (GEM) level of $1.5 \mathrm{ng} \mathrm{m}^{-3}$ is equivalent to 168 parts per quadrillion by volume $\left(\mathrm{ppq}_{\mathrm{v}}\right)$. There is no other atmospheric compound being measured routinely, continuously, and automatically at this ultralow concentration. These features limit the scientific research community's long-term ability to measure atmospheric $\mathrm{Hg}$ concentrations worldwide. Sampling and analysis of atmospheric $\mathrm{Hg}$ is conducted most commonly as GEM and/or TGM because of their greater abundance, even though both manual and automatic methods have been developed for different $\mathrm{Hg}$ forms to suit the measurement and monitoring application. The most common sampling method employed relies on adsorption on gold amalgam and then, either directly or indirectly, through a stepwise process of thermal desorption and final detection (usually by cold-fiber atomic absorption spectroscopy, CVAAS, or cold-fiber atomic fluorescence spectroscopy, CVAFS). However, there are several gaps in our current knowledge to be solved. Firstly, the atmospheric chemistry of $\mathrm{Hg}$ remains poorly understood, especially the oxidation pathways by which GEM is converted to GOM, the reduction pathway that converts GOM back to GEM, and the gas-particle partitioning. This is partially due to the need for the identification of the chemical forms of oxidized $\mathrm{Hg}$ in the atmosphere and the methods to measure these compounds individually. In addition, the limitations and potential interferences with our current measurement methods have not been adequately investigated; thus alternate methods to measure atmospheric $\mathrm{Hg}$ are needed. Given the uncertainty and restrictions associated with automated and/or semi-automated Hg measurements (Gustin et al., 2013; Pirrone et al., 2013), particularly in responding to the technical needs of an expanding $\mathrm{Hg}$ global observation network, we developed a reliable, sensitive, and inexpensive surface for atmospheric $\mathrm{Hg}$ detection. In particular, we investigated and demonstrated the utility of composite nanofibrous electrospun layers of titania decorated with gold nanoparticles (AuNPs) to obtain nanostructured materials capable of adsorbing GEM as a useful alternative system for making regional and global estimates of air $\mathrm{Hg}$ concentrations. Previously developed methods and new sampling systems, such as passive samplers, have been used to understand the long-term global distribution of persistent organic pollutants (POPs; Harner et al., 2003; Pozo et al., 2004). Other passive samplers for both TGM and GOM collection on the basis of diffusion have been constructed using a variety of synthetic materials (i.e., gold and silver surfaces, and sulfate-impregnated carbon) and housings (Lyman et al., 2010; Gustin et al., 2011; Zhang et al., 2012; Huang et al., 2014). However, because of 
the differences in the design of passive samplers, ambient air $\mathrm{Hg}$ concentrations quantified by various samplers may not be comparable. In addition, the sampling rates (SRs) using the same passive samplers may depend on the environmental conditions and atmospheric chemistry at each site. It has also been highlighted that the performance of passive samplers may be influenced by meteorological factors (e.g., $T{ }^{\circ} \mathrm{C}$, $\mathrm{RH}$, and wind speed), therefore inducing bias to the results of passive sampling (Plaisance et al., 2004; Sderstrm and Bergqvist, 2004). On the other hand, an incentive for developing simple and cost-effective samplers that are capable of monitoring over an extended period and require no technical expertise even at remote locations is now clear. In this work, we describe an alternative approach adopted in the place of conventional ones, demonstrating that the combination of the affinity of gold for $\mathrm{Hg}$ and a nanoscale-sized framework of titania provided the chance to create promising sensors for environmental monitoring in real time characterized by high sensitivity to the analyte. The novel sensor is a relatively simple and low-cost method for the measurement of the most abundant $\mathrm{Hg}$ form in ambient air (TGM or GEM) due to reusable parts and simple deployment steps. Further, we have evaluated the applicability of this measurement technique with respect to real environmental conditions, highlighting future directions for research on airborne $\mathrm{Hg}$ determination. The TGM-GEM sensor surface described here could be deployed in a global network such as GMOS; a permanent network of ground-based monitoring sites and observations of $\mathrm{Hg}$ and/or related species on a global scale with remote sensors would in fact be highly desirable. These data are needed to test and validate model processes and predictions, understand the source-receptor relationships, understand longterm changes in the global $\mathrm{Hg}$ cycle, and would help policy makers to set regulations for different areas. The sensor features are related to the nanofibrous scaffold of titania capable of growing gold nanoaggregates through photocatalysis that are tunable in size and shape. Such a nanostructured layer, fabricated with electrospinning technology, firstly improves sensor features with respect to those of compact films, by enhancing the global number of analyte-sensor binding sites and reducing some bulk drawbacks. Secondly, the combination of metal oxides and metal nanostructures improves the sensitivity, allows the sensor to work at room temperature, tunes the selectivity towards different gas species by adjusting the surface-to-volume ratio of nanosized structures, and affects the sensor lifetime. Morphological, optical, and electrical aspects, as well as the sensing measurements of GEM fibers in air have been reported and discussed. When designed, the resulting $\mathrm{Hg}$ adsorbent or absorbent material was expected to be suitable for novel $\mathrm{Hg}$ sensor fabrication, since a similar nanofibrous scaffold doped with AuNPs was described in the literature as a filtering system capable of adsorbing and removing $\mathrm{Hg}$ vapor from the environment with an efficiency of nearly $100 \%$ (Yuan et al., 2012). In previous work (Macagnano et al., 2017, 2015a), the authors reported a high sensitivity of the sensor capable of detecting up to dozens of $\mathrm{ppt}_{\mathrm{v}}$ despite the long time needed to reveal the analyte at these concentrations in air. In this work, the chance to apply the sensor in polluted sites and in real time has been presented and described.

\section{Materials and methods}

\subsection{Chemicals}

All chemicals were purchased from Sigma-Aldrich (St. Louis, MO, USA) and used without further purification: polyvinylpyrrolidone (PVP; Mn 1300000 ), titanium isopropoxide (TiiP; 99.999\%), gold (III) chloride hydrate $\left(\mathrm{HAuCl}_{4} ; 99.999 \%\right)$, anhydrous ethanol $\left(\mathrm{EtOH}_{\mathrm{a}}\right)$, and glacial acetic acid $\left(\mathrm{AcAc}_{\mathrm{g}}\right)$. Ultrapure water $\left(5.5 \times 10^{-8} \mathrm{Scm}^{-1}\right)$ was produced by Milli-Q EMD (Millipore Corporation, Darmstadt, Germany).

\subsection{Electrospinning technology}

Electrospinning (ES) is a widely used technique for the electrostatic production of nanofibers, during which an electric field is used to make polymer fibers with diameters ranging from $2 \mathrm{~nm}$ to several micrometers from polymer solutions (or melts). It is currently the most economic, versatile, and efficient technology to fabricate highly porous membranes made of nanofibers and/or microfibers for sensors (Macagnano et al., 2015b). It is based on the application of a high-voltage difference between a spinneret ejecting a polymeric solution and a grounded collector. The jet of solution is accelerated and stretched by the external electric field while traveling towards the collector, leading to the creation of continuous solid fibers as the solvent evaporates. The electrospinning apparatus used in the present study (designed and assembled in CNR laboratories) is comprised of a homemade clean box equipped with temperature and humidity sensors, a syringe pump (KDS 200; KD Scientific, Holliston, MA, USA), a grounded rotating cylindrical collector ( $45 \mathrm{~mm}$ diameter), and a high-voltage oscillator $(100 \mathrm{~V})$ driving a high-voltage (ranging from 1 to $50 \mathrm{kV}$ ) high-power AC-DC (alternating current to direct current) converter. The electrospinning solution $\left(7.877 \times 10^{-5} \mathrm{M}\right)$ was prepared by dissolving PVP in $\mathrm{EtOH}_{\mathrm{a}}$ and stirring $(2 \mathrm{~h})$. A $2 \mathrm{~mL}$ aliquot of a $1: 4(w / v)$ solution of TiiP solved in a $1: 1(v / v)$ mixture of $\mathrm{AcAc}_{\mathrm{g}}$ and $\mathrm{EtOH}_{\mathrm{a}}$ was freshly prepared and added to the $2.5 \mathrm{~mL}$ PVP solution under stirring in order to obtain a $1.95(w / w)$ TiiP / PVP final ratio. Both mixtures were prepared in a glove box under a low humidity rate $(<7 \% \mathrm{RH})$. The syringe filled with the TiiP/PVP solution and housed in the syringe pump was was connected to a positive DC voltage $(6 \mathrm{kV})$ and set perpendicular to a grounded rotating collector at $15 \mathrm{~cm}$ of distance. The substrates were fixed through suitable holders onto the collector $\left(600 \mathrm{rpm}, 21^{\circ} \mathrm{C}\right.$, and $\left.35 \% \mathrm{RH}\right)$ and processed (feed rate $150 \mathrm{~mL} \mathrm{~h}^{-1}$ ) for 20 min to obtain scaf- 
folds for the sensors. After deposition, $\mathrm{PVP} / \mathrm{TiO}_{2}$ composite nanofibers were left for some hours at room temperature to fully undergo the self-hydrolysis of TiiP (Li et al., 2004) and then annealed under an oxygen atmosphere (muffle furnace) using a thermal ramp from room temperature up to $550^{\circ} \mathrm{C}$ $\left(1^{\circ} \mathrm{C} \min ^{-1} ; 4 \mathrm{~h}\right.$ dwell time) in order to remove PVP and crystallize the metal oxide (anatase).

\subsection{Transducers: interdigitated electrodes}

The transducer adopted in the present work to convert the physiochemical interactions of analytes with the different polymer fibers in an electrical signal was an interdigitated electrode (IDE; Bakir et al., 1973; James et al., 2013). Specifically, the transducer consisted of 40 pairs of electrodes $(150 \mathrm{~nm}$ in electrode thickness, $20 \mu \mathrm{m}$ in gap and electrode width, and $5620 \mu \mathrm{m}$ in length); it was manufactured in CNR laboratories through a standard photolithographic process (liftoff procedure) followed by Ti sputtering and Pt evaporation suitable to generate electrodes of the size reported above on a 4 in. oxidized silicon wafer. After electrospinning deposition, all the electrical signals of the resulting chemoresistors were recorded by an electrometer (Keithley Instruments, Inc., Cleveland, OH, USA; model 6517).

\subsection{Titania nanofibers}

Upon calcination, the diameters of the fibers extraordinarily shrank: the mean diameters of the fibers were estimated through image analyses to be approximately within the range of $60-80 \mathrm{~nm}$. Specifically, the resulting fibers appeared fine and rough at the surface with a fairly homogeneous fabric. The absence of beads and the good quality of the long and continuous fibers was confirmed through SEM micrographs. A highly porous and dense network of nanofibers covering the electrodes was observed, showing interconnected void volumes (porosity) and high surface-to-volume ratios (specific surface area). Zampetti et al. (2013) reported that such a fibrous layer showed $99 \%$ of pores with an area of less than $10 \mu \mathrm{m}^{2}$ with more than $80 \%$ pores being $<1 \mathrm{~mm}^{2}$.

\subsection{AuNPs $/ \mathrm{TiO}_{2} \mathrm{NFs}$ photocatalytic decoration}

Exploiting the photocatalytic properties of $\mathrm{TiO}_{2}$, gold nanoparticles were selectively grown under UV light irradiation on the electrospun titania nanofibers through the photoreduction of $\mathrm{HAuCl}_{4}$ in the presence of an organic capping reagent (PVP). The resulting fibrous scaffolds were dipped into an aqueous solution containing $\mathrm{HAuCl}_{4}$ and $\mathrm{PVP}$ $\left(1.5 \times 10^{-3} \mathrm{M}\right.$ and $0.1 \mathrm{M}$, respectively) and exposed to UV light irradiation for specified intervals (UV lamp $365 \mathrm{~nm}$; Helios; Italquartz, Calenzano, Italy). Depending on the gold nanoparticle sizes that were formed in photocatalysis, the dip solution changed from light yellow to purple. Samples were rinsed extensively with water and then air dried. Before the morphological, electrical, and sensing measurements, the samples were heated at $450{ }^{\circ} \mathrm{C}$ per $1 \mathrm{~h}$ to eliminate the PVP traces. Morphological characterization was provided through scanning electron microscopy (SEM; Jeol, Tokyo, Japan; JSM 5200; $20 \mathrm{keV}$ ) with pictures captured at $5 \mathrm{kV}$ of accelerating voltage. AFM (atomic force microscopy) micrographs were taken in tapping mode using 190Al-G tips, $190 \mathrm{kHz}$, and $48 \mathrm{~N} \mathrm{~m}^{-1}$ (Nanosurf AG, Liestal, Switzerland; FlexAFM). TEM (C-TEM; control transmission electron microscopy) micrographs were performed at $200 \mathrm{keV}$ with an analytical double-tilt probe. TEM specimens were prepared by gently scraping the $\mathrm{TiO}_{2}$ nanofibrous layer electrospun onto the silicon support and then collecting the nanofibers through adhesion upon contact with holey carbon thin film. UV-vis spectra were provided by a spectrophotometer (UV2600; Shimadzu Corporation, Kyoto, Japan) by analyzing quartz slices coated with nanofibers. These substrates were able to collect fibers by electrospinning $(20 \mathrm{~min})$ and were then subjected to calcination according to the procedure described above; the final step was UV irradiation in the aqueous solution. The fibrous layer stayed stuck to the substrate if the thickness was thin enough. Longer depositions caused curling of the fibers during the calcination process.

\subsection{Measurement setup}

The sensor was placed in a suitable PTFE-made measurement chamber $(0.7 \mathrm{~mL}$ volume) connected to an electrometer (Keithley 6517) capable of measuring the current flowing through the IDE when a fixed potential was applied to it and sending data to a PC. Dynamic measurements were carried out at room temperature using (i) a four-channel MKS 247 managing four MKS mass flow controllers (MFC) set in the range of 0-200 sccm and (ii) an Environics S4000 (Environics, Inc., Tolland, CT, USA) flow controller comprised of three MFCs supplying different flow rates (up to 500, 250, and $25 \mathrm{sccm}$ ) managed by its own software. Pure air (5.0; Praxair-Rivoira, Milan, Italy) was used as a gas carrier. A homemade PTFE (polytetrafluoroethylene) permeation tube filled with a suitable amount of $\mathrm{Hg}^{0}$ was included within the delivery system to obtain set dilutions of $\mathrm{Hg}$-saturated vapors. The tube was immersed in a thermostatically controlled bath; thus the desired $\mathrm{Hg}^{0}$ concentration delivered to the sensor was achieved by tuning both the temperature of the permeation tube and the dilution flow. The $\mathrm{Hg}^{0}$ concentration was checked by a Tekran ${ }^{\circledR}$ 2537A analyzer (Toronto, ON, Canada). Responses were calculated as $\Delta \mathrm{I} / \mathrm{I}_{0}$, where $\Delta \mathrm{I}$ was the current variation and $\mathrm{I}_{0}$ was the current when synthetic pure dry air flowed. The sensor was restored after a quick thermal shot at $450^{\circ} \mathrm{C}$ under a flow of pure air.

\section{Results and discussion}

Nonwoven mats made of PVP and amorphous $\mathrm{TiO}_{2}$ were obtained through the combination of electrospinning and sol- 
(a)

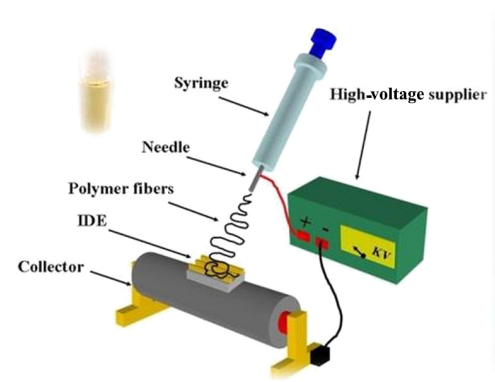

(b)

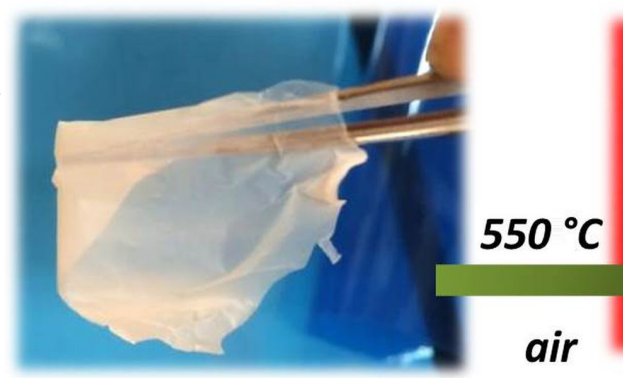

(c)

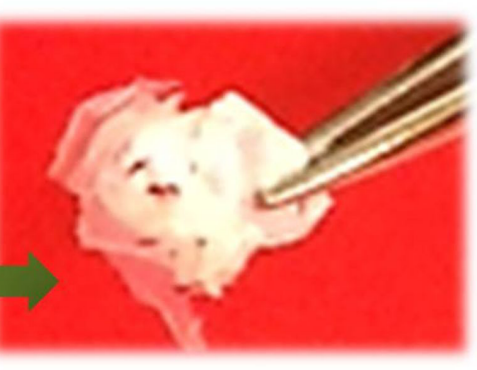

Figure 1. A sketch of an electrospinning setup comprised of a syringe and a grounded rotating cylinder collector where the samples are placed for coverage (a); a piece of TiiP/PVP nanofibrous fabric removed from the substrate after $1 \mathrm{~h}$ of electrospinning deposition (b); a reddish purple aqueous solution of $\mathrm{HAuCl}_{4} / \mathrm{PVP}$ after UV light irradiation treatment and (c) a piece of the $\mathrm{TiO}_{2}$ (anatase) nanofibrous fabric obtained after TiiP/PVP annealing.

(a)

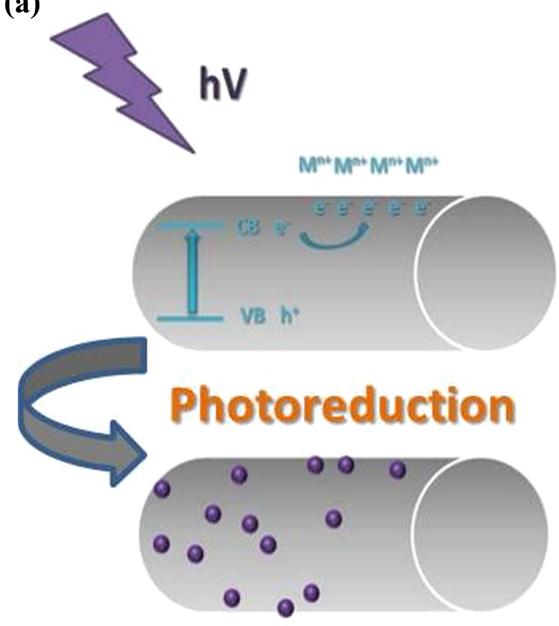

(b)

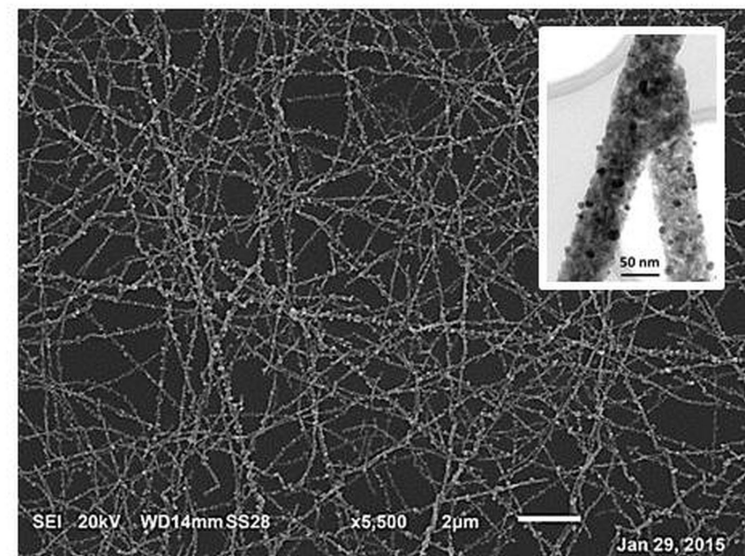

Figure 2. A sketch of the photocatalytic process occurring on the fiber surface (a); an SEM picture of a dense nanofibrous network of AuNPs $/ \mathrm{TiO}_{2}$ coating a silicon wafer (b); and a C-TEM micrograph of fibers finely decorated with gold nanoparticles (the darkest ones) bound without using any additional linker (inset).

gel techniques (Fig. 1). The ES deposition proceeded for $20 \mathrm{~min}$ on oxidized silicon wafers and IDEs properly fixed on the surface of a conducting and rotating collector to form nanofibrous layers characterized by high surface areas and relatively small pore sizes (Zampetti et al., 2013). By changing the deposition time, both the thickness and the consistency of the mats changed. More specifically, a $1 \mathrm{~h}$ deposition provided the formation of a thicker, white, soft fabric that is hygroscopic, soluble in both water and polar solvents, and easily peeled off (Fig. 1); instead, a 20 min deposition generated a fibrous film adhering to substrates too thin to be weeded and thus preferred for sensor fabrication. The calcination process caused a complete degradation of PVP with the formation of crystalline $\mathrm{TiO}_{2}$ (anatase) and a significant shrinkage in the fiber dimensions $(60-80 \mathrm{~nm}$ diameter; 5$40 \mathrm{~nm}$ grain size). By exploiting the photocatalytic properties of titania (anatase), a tunable decoration of fibers with gold nanoparticles could be achieved by dipping the fibrous mats in a proper aqueous solution $\left(\mathrm{HAuCl}_{4} ; \mathrm{PVP}\right)$ under UV light irradiation (Li et al., 2004; Macagnano et al., 2015a). The photocatalytic reaction was confirmed by the color change of the solution (reddish purple from light yellow; Fig. 1). By changing both the UV irradiation exposure time and the PVP concentration as a capping reagent, the morphology, size, and density of the gold nanoparticles could be tuned (Macagnano et al., 2017).

In the present work, among a series of differently coated fibrous layers, only the fibrous nanocomposites that were conductive at room temperature were selected; their electrical and sensing features were then investigated. The controlled gold deposition was due to the photo-excited electrons on the surface of $\mathrm{TiO}_{2}$ nanofibers that were able to reduce the gold ions, thus inducing gold metal deposition (Fig. 2 sketch). The capping reagent was responsible for the shape 


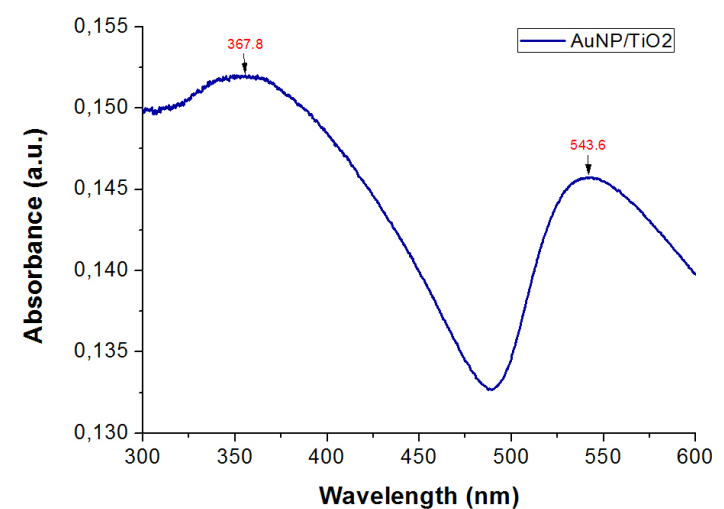

Figure 3. UV-vis spectrum of a titania nanofibrous network after gold decoration $\left(\mathrm{TiO}_{2}: 367.8 \mathrm{~nm}\right.$; Au NPs: $\left.543.6 \mathrm{~nm}\right)$.

of the particles. The surfaces of the nanofibers, as observed in SEM micrographs (Fig. 2a), appeared densely decorated with globular nanoparticles. In the C-TEM image (Fig. 2, inset) the gold nanoparticles appeared darker with spherical or quasi-spherical shapes. The single particle sizes ranged between 2 and $20 \mathrm{~nm}$ with a $7.8 \pm 3 \mathrm{~nm}$ average diameter (Macagnano et al., 2017). Gold nanoparticles grew directly onto the nanofibers, and their adhesion appeared relatively strong (despite van der Waals forces), since they resisted both water rinsing and fiber scratching for TEM analyses.

As a result of the photocatalytic process, the white porous mat became purplish violet. As reported in the spectrum of the $\mathrm{AuNP} / \mathrm{TiO}_{2}$ hybrid system, a characteristic absorbance band appeared at about $543 \mathrm{~nm}$, which corresponded to the surface plasmon resonance (SPR) of the AuNPs (Sun and $\mathrm{Xia}, 2003)$. A red shifting and broadening of the absorbance band was observed with the increase in AuNP size and fiber loading, respectively (data not shown). The color strictly depends on the size of the nanoparticles and then their agglomeration at the solid state. According to Bui et al. (2007), such a band-broadening phenomenon is due to the electric dipoledipole interactions and coupling occurring between the plasmons of neighboring particles, whereas nanoparticle agglomeration phenomena occurred.

Due to these features, UV-vis absorption spectroscopy has been used in the literature as a technique to reveal the changes in the size, shape, and aggregation of metal nanoparticles in liquid suspension after exposure to heavy metals as $\mathrm{Hg}^{0}$ (Morris et al., 2002). Both the blue-shifted wavelength and its extent were proportional to the amount of $\mathrm{Hg}^{0}$ that entered the liquid suspension. Similarly, when the golddecorated nanofibers of titania collected on a quartz slice were exposed to $\mathrm{Hg}^{0}$ vapors ( $2 \mathrm{ppm}$ ) in air for $15 \mathrm{~min}$, significant blue shifting was reported $(\sim 3 \mathrm{~nm}$; Fig. 4$)$ due to the atomic adsorption of GEM on the surface. The nanoparticles could be regenerated by heating the sample at $550{ }^{\circ} \mathrm{C}$ for $3 \mathrm{~min}$, thus removing all the $\mathrm{Hg}^{0}$ adsorbed. Their recovery was confirmed by the achievement of the original wavelength

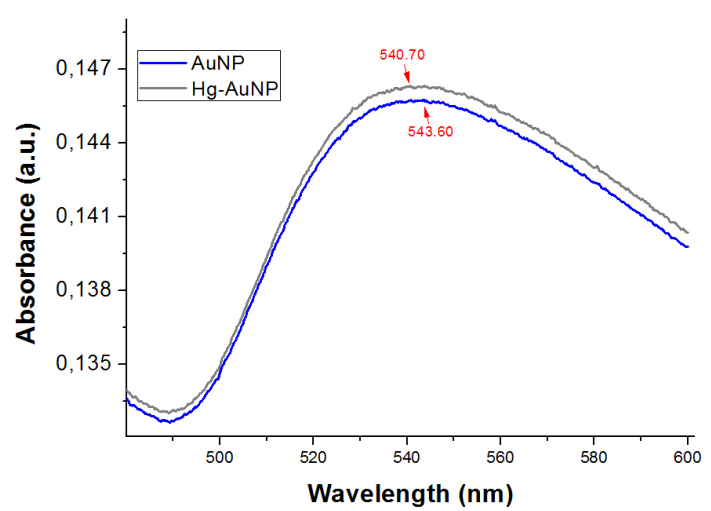

Figure 4. UV-vis spectra of $\mathrm{AuNPs} / \mathrm{TiO}_{2}$ nanofibers before (blue) and after a $15 \mathrm{~min}$ exposure to $2 \mathrm{ppm}$ of $\mathrm{Hg}^{0}$ (gray).

(a)

(b)

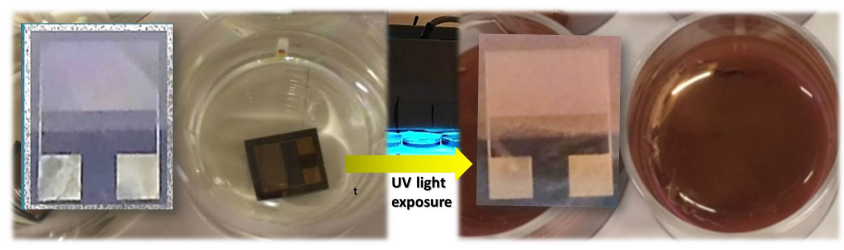

Figure 5. The chemosensor fabrication and final structure: IDE dipped (a) and exposed to UV light (b) for gold decoration.

values (UV-vis spectra). The regeneration process could be carried out dozens of times without any noticeable NP deterioration. Similarly, the $\mathrm{TiO}_{2}$ nanofibrous layers coating the metal electrodes of the transducers (Fig. 5) changed color after photocatalytic treatment (from white to pink).

The IDE layout (Fig. 5) is comprised of a set of interdigitated electrodes that occupies an area approximately $3 \times 5 \mathrm{~mm}$, is completely coated with the sensitive fibers, and has two bonding pads $(2 \times 2 \mathrm{~mm})$ that will be connected to the electrometer (DC voltage). Such a planar interdigitated electrode configuration is most commonly used for conductometric sensing applications.

Figure 6 depicts the current-voltage (I-V) curve of a chemosensor under a synthetic dry air flow. However, the curve shape was unaltered when air or nitrogen was flushed over the fibers (Macagnano et al., 2015a), suggesting that oxygen concentrations poorly affected the electrical properties of such a chemoresistor. The resistance value of the IDE coated with $\mathrm{TiO}_{2}$ nanofibers before photocatalysis was too high at room temperature to contribute directly to the final current value. The resulting linear shape (ohmic behavior) within the selected voltage range (from -3 to $+3 \mathrm{~V}$ ) showed a constant resistance value for the sensor. The very low value of resistance $(\sim 1.2 \mathrm{k})$ provided the chance to work at low voltage, with consequent effects on the energy consumption as well as the lifetime of the material. Moreover, the linearity of the I-V curve let us suppose that the sensing scaffold 


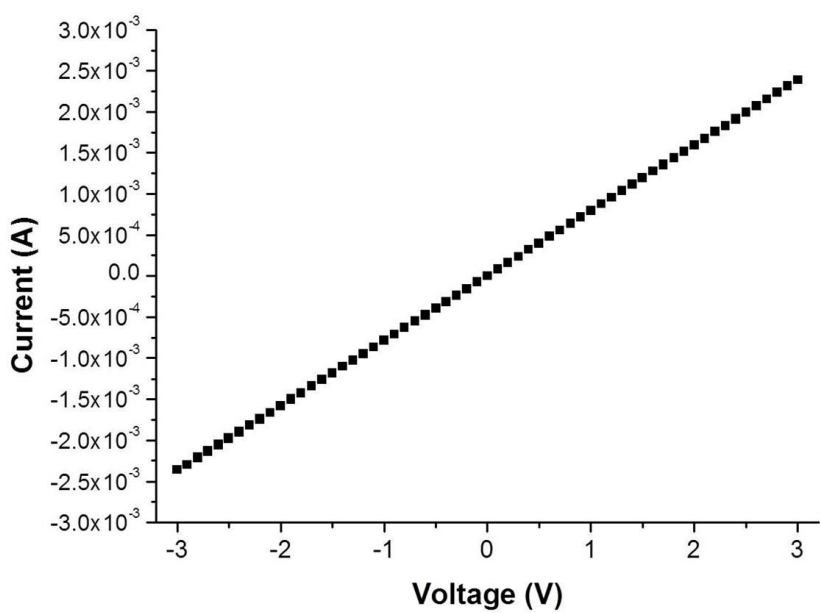

Figure 6. The chemosensor current-voltage curve.

had a good adhesion to the metal electrodes. The electron conductivity has been assumed to occur according to the percolation model (Macagnano et al, 2017; Müller et al., 2003), since the titania at room temperature was expected to be an insulating matrix. When it is metal doped, the electron conductivity is ruled by thermally activated electron tunneling from one metal island (gold nanoparticles) to the other. However, the conductivity of the nanocomposite is lower than that of pure metal (gold) because the electron mean free path is greatly reduced due to the presence of the dielectric (the titania crystals). The electrical features, such as the reproducibility of the fabrication process, of this conductive device have been previously investigated by the authors (Macagnano et al., 2017, 2015a), showing encouraging results for the development of a low-cost sensor for mercury detection. However, in spite of the high sensitivity (LOD: 2 ppt) of the sensor, a too-long response time was necessary to detect traces of $\mathrm{Hg}^{0}$, especially if compared to the monitoring instrumentation (Ghaedi et al., 2006; Sanchez-Rodas et al., 2010; Ferrua et al., 2007) commonly involved in GEM detection. The long response time was in part due to the layout of the measuring system, since the sensor was previously housed in a quartz bottle of $100 \mathrm{~mL}$ in volume. Additional time is caused by the adsorption of $\mathrm{Hg}^{0}$ traces from the surrounding environment (measuring chamber) up to the achievement of a sufficient number of $\mathrm{Hg}^{0}$ atoms adsorbed on the surface sensor to be electrically revealed. However, this sensor looks extremely encouraging if compared to other sensors currently involved in detecting mercury in air (Drelich et al., 2008; Kabir et al., 2015; Sabri et al., 2009; Mohibul Kabir et al., 2015; Raffa et al., 2006; James et al., 2012, 2013; Chemnasiri and Hernandez, 2012; Sabri et al., 2011; Keebaugh et al., 2007; Crosby, 2013; McNicholas et al., 2011).

Many sensors have been designed and investigated to detect the several forms of mercury. Most of them have exploited the strong affinity between mercury and gold (Ford
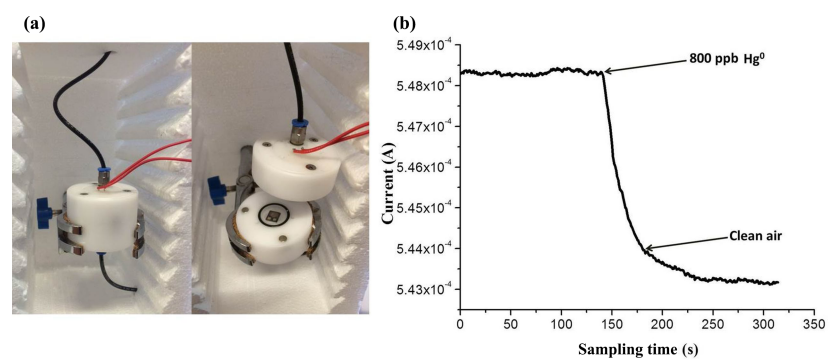

Figure 7. A homemade measurement chamber to house the chemosensor for laboratory experiments (left); a plot depicting the transient response curve to $800 \mathrm{ppb} \mathrm{Hg}^{0}(V=0.3 \mathrm{~V})$.

and Pritchard, 1971; Joyner and Roberts, 1973). Several studies have documented changes in the electrical properties, work function, and resistance of thin gold films upon exposure to various concentrations of mercury vapor. For instance, an array of microcantilevers with different sizes developed by Drelich et al. (2008) could measure different ranges of mercury concentration (between 37 and $700 \mathrm{\mu g} \mathrm{m}^{-3}$ ) and were capable of revealing up to $10 \mathrm{pg} \mathrm{Hg}^{0}$ adsorbed. However, their sensing system required both a dust-free gas carrier and a heating procedure $\left(350^{\circ} \mathrm{C}\right.$ for $20 \mathrm{~min}$ ) to regenerate the sensors. Gold-based conductometric sensors, too, have been designed and used to reveal mercury vapor through their electrical resistance changes (Raffa et al., 2006), but their sensitivity often seemed poor (about $1 \mu \mathrm{g} \mathrm{m}^{-3}$ ). Quartz crystal microbalance (QCM) devices, too, have been used as $\mathrm{Hg}^{0}$ vapor sensors (Sabri et al., 2009) due to their high portability, selectivity, and unnecessary sample pretreatments. Their absorptive capacity was improved $\left(700 \mathrm{n} \mathrm{cm}^{-2}\right.$ ) when the gold electrodes were made rough (more binding sites). However, additionally to the natural affinity of gold for mercury, the increased facility for producing and depositing nanoparticles with noble metals facilitated their use as possible sensors, especially in aqueous environments (Nolan and Lippard, 2008; Chemnasiri and Hernandez, 2012; Ratner and Mandler, 2015; Dong et al., 2015). James et al. (2012) developed a highly sensitive chip working in an LSPR mode based on gold nanoparticles $(5 \mathrm{~nm}$ diameter) to monitor $\mathrm{Hg}^{0}$ vapors. Such a system was able to linearly detect mercury concentrations from 1 to $825 \mu \mathrm{g} \mathrm{m}^{-3}$, but it was strictly related to the flow rate: increasing the flow velocity (and mass transfer rate) increased the peak shift rate. The time resolution was limited by the rate of adsorption, which increased with the Reynolds number; at the greatest flow rate tested (57 LPM), an ambient mercury measurement $\left(1 \mathrm{ng} \mathrm{m}^{-3}\right)$ needed $410 \mathrm{~h}$ to shift $1 \mathrm{~nm}$, but accelerating the flow rate could reduce the time resolution.

Gold thin film technology has been recently adopted in a commercial portable device to detect mercury (Jerome ${ }^{\circledR} \mathrm{J} 405$ mercury vapor analyzer) with a $0.01 \mu \mathrm{g} \mathrm{m}^{-3}$ resolution and a $750 \pm 50 \mathrm{cc} \mathrm{min}^{-1}$ flow rate (http://www.azic.com/jerome/ j405/). A series of scrubbers and filtering systems are able 


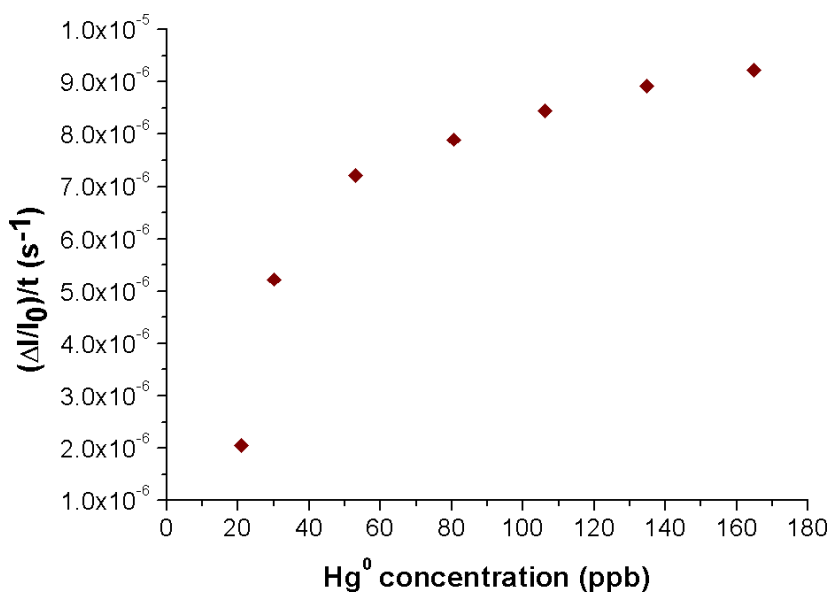

Figure 8. The normalized sensor response rate to the increasing concentration of vapor elemental mercury.

Table 1. Linear fitting parameters of $10 \mathrm{~min}$ sensor responses to $21 \mathrm{ppb} \leq\left[\mathrm{Hg}^{0}\right] \leq 106 \mathrm{ppb}$.

\begin{tabular}{lrrr}
\hline $\mathrm{ppb}_{\mathrm{v}}$ & $\left(\Delta \mathrm{I} / \mathrm{I}_{0}\right) \mathrm{s}^{-1}$ & $\mathrm{SE}( \pm)$ & $R^{2}$ \\
\hline 21 & $-7.12602 \mathrm{E}-10$ & $1.75521 \mathrm{E}-11$ & 0.86 \\
33 & $-1.50647 \mathrm{E}-9$ & $1.05521 \mathrm{E}-10$ & 0.91 \\
39 & $-1.78067 \mathrm{E}-9$ & $1.02615 \mathrm{E}-10$ & 0.91 \\
40 & $-1.85901 \mathrm{E}-9$ & $1.01833 \mathrm{E}-10$ & 0,92 \\
53 & $-2.44657 \mathrm{E}-9$ & $4.24993 \mathrm{E}-11$ & 0.91 \\
70 & $-3.19082 \mathrm{E}-9$ & $2.55882 \mathrm{E}-11$ & 0.93 \\
106 & $-4.83599 \mathrm{E}-9$ & $2.67462 \mathrm{E}-10$ & 0.88 \\
\hline
\end{tabular}

to reduce the effects of interferents on the gold-mercury interaction. The flow rate and the measuring system layout were key parameters in the proper working of the device. These features also seem to be significant for the ES-based chemosensor.

The measuring chamber was designed to reduce the volume $(0.7 \mathrm{~mL})$ and expose the fibers to the gas entry (Fig. 7). Such a measuring layout was designed to allow the fibrous network to be exposed to the mercury atoms as delivered into the sensor chamber.

Sensing measurements, i.e., the current (or resistance) changes, were carried out in a continuous mode. The sensor measurements resulted in a change of the whole current (or resistance, i.e., $\mathrm{I}=V / R$ ) according to Ohm's law. Firstly, the sensor was exposed to a flow of $\mathrm{Hg}^{0}$ in air with a concentration of $800 \mathrm{ppb}_{\mathrm{v}}$ for 1 min (Fig. 7, right), and then air was flowed through the measuring chamber to clean the sensor surface. A rapid decrease in current was recorded $\left(1.056 \times 10^{-7} \mathrm{~A} \mathrm{~s}^{-1}\right)$ when $\mathrm{Hg}^{0}$ entered the measuring chamber. The current curve trend slightly changed when clean air entered, quickly stabilizing to about the same current values reached for $\mathrm{Hg}^{0}$ adsorption. Such an effect was probably due to the $\mathrm{Hg}^{0}$ still housed inside the deliv-

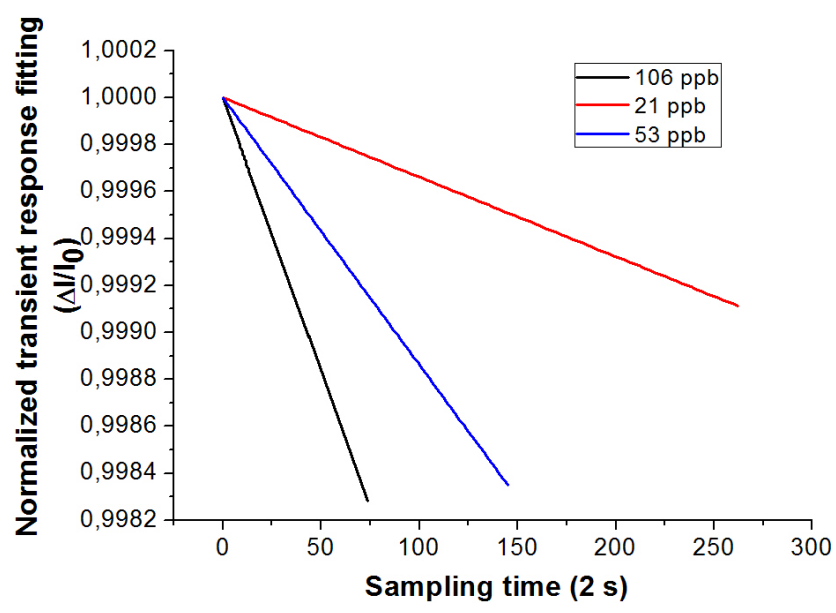

Figure 9. Linear fitting of the normalized sensor response within the first $10 \mathrm{~min}$.

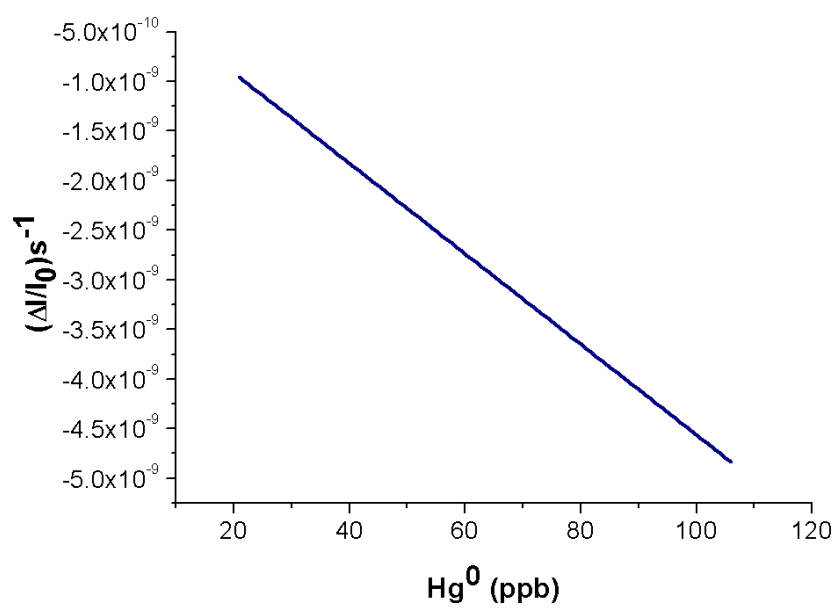

Figure 10. Linear relationships between the normalized response time and the $\mathrm{Hg}^{0}$ concentration within the range of 20 and $100 \mathrm{ppb}_{\mathrm{v}}$.

ering tubes. The polluted line contribution was confirmed by further measurements (data not shown), where the slow current decrease completely disappeared when clean air never passed through the part of the tubes that had carried $\mathrm{Hg}$ vapors. Due to the strong affinity between $\mathrm{Au}$ and $\mathrm{Hg}^{0}$, a 3 min thermal treatment was necessary to remove mercury from the layer and obtain the same starting current value.

Figure 8 depicts the normalized sensor response rate, i.e., the normalized current change per second, toward the increasing concentration of GEM (ranging between 20 and $160 \mathrm{ppb}_{\mathrm{v}}$ ). Within this study, the selected flow rate was kept at $50 \mathrm{sccm}$ in order to avoid turbulence effects. The resulting logarithmic curve describes the relationship between $\mathrm{Hg}^{0}$ concentration and the response time; small variations in $\mathrm{Hg}^{0}$ concentration up to $80 \mathrm{ppb}_{\mathrm{v}}$ were able to deeply change the response rate. In contrast, a higher concentration seemed to only weakly affect this sensing feature. Thus, since a strong relationship is recorded between the concentration and the 
response time of mercury under $80 \mathrm{ppb}_{\mathrm{v}}$, it is possible to find a correlation between the slope of the transient responses within the early minutes of the sensor response and definite concentrations of $\mathrm{Hg}^{0}$ in air. Figure 9 depicts the linear fitting of $10 \mathrm{~min}$ sensor responses when increasing concentrations of mercury were flowed over the sensor. The related data are reported in Table 1.

A linear relationship has been reported between the response rate and the concentration of $\mathrm{Hg}$, according to Eq. (1):

$$
\begin{aligned}
& y=\left(-4.56226 E^{-11}\right) \cdot\left[\mathrm{Hg}^{0}\right],\left[\mathrm{Hg}^{0}\right]<100 \mathrm{ppb}, \\
& \mathrm{SE}: \pm 1.504 E^{-12}, R^{2}=0.99675 .
\end{aligned}
$$

Therefore, when the concentration of $\mathrm{Hg}$ increased, the response curve slope changed too linearly, allowing a limit of detection of about $1 \mathrm{ppb}_{\mathrm{v}}$ for a $10 \mathrm{~min}$ exposure $(50 \mathrm{sccm})$. Regarding the main interfering compounds, at room temperature and in dark conditions the measured current should be due to AuNPs decorating titania fibers; only chemical compounds interacting with gold are therefore expected to be mostly responsible for the current changes (i.e., halides and sulfides). Thus in a blend of other chemicals, this sensor has been designed as a relatively selective sensor able to greatly decrease the environmental disturbances, allowing the investigator or manufacturer to design and then implement easier strategies to prevent contamination from the environment (selective filtering systems or coatings). Among the common potential contaminants, the authors previously investigated water vapor influence $(\% \mathrm{RH})$ and reported no effects on the electrical signals (Macagnano et al., 2015a).

\section{Conclusions}

The adopted sensing strategy focused on the strong affinity of mercury for gold combined with the nanostructure properties. By exploiting the photocatalytic properties of electrospun titania nanofibers, a novel conductometric sensor has been designed and fabricated to detect GEM in air. Electrospinning technology has been used successfully to create a 3-D framework of titania covering the electrode-sensing area of the properly designed chemoresistors (IDEs). By exploiting the photocatalytic properties of titania, AuNPs have been grown on nanofibers. Such a sensor was able to work at room temperature and was sensitive to $\mathrm{Hg}^{0}$, even after a few minutes of exposure to polluted air. Since it is composed of titania and gold, it seems to be robust and resistant to common solvents and VOCs in the air (as reported in the literature). Preliminary results suggest that the short thermal treatments necessary to desorb mercury from AuNPs did not seem to affect the electrical properties of the device. Depending on the sampling strategy, a sensing device based on such a chemosensor could be designed for real applications, specifically for the real-time monitoring of polluted sites. A few minutes of air sampling are sufficient to quantify the con- centration of mercury in the air in the range between 20 and $100 \mathrm{ppb}_{\mathrm{v}}$ (LOD: $1 \mathrm{ppb}$ ), without using traps or gas carriers. Changing parameters such as the flow rate, density, and size of the gold particles is expected to significantly improve the LOD and the response time. Finally, a modified transducer layout could be designed to better exploit the adsorptive capacity of the 3-D nanofibrous framework. However, further investigations are necessary to also assess the effects of the physical parameters of the environment, such as temperature fluctuations and UV light (that should activate the titania surface in adsorbing oxidized $\mathrm{Hg}$ ), as well as chemical ones, such as volatile organic compounds and gas (like halides and sulfides), which are known to interfere with the adsorption process of $\mathrm{Hg}^{0}$ on gold.

Data availability. All the data reported within the paper resulted from electrical and optical measurements carried out in the laboratory using innovative materials and devices. The data have been uploaded onto the GMOS central database and are available upon request at http://sdi.iia.cnr.it/geoint/publicpage/GMOS/gmos_ historical.zul (GMOS Database, 2014). The GMOS database coordinated by the CNR-IIA is part of the GMOS CyberInfrastructure (CI), which supports advanced data acquisition, storage, management, integration, mining, and visualization. All GMOS stations provide near-real-time raw data that are archived and managed for the QA/QC process by the GMOS-Data Quality Management System (G-DQM), a web-based application which is part of the GMOSCI, developed by the CNR-IIA in 2011, and is currently ongoing.

Competing interests. The authors declare that they have no conflict of interest.

Acknowledgements. The research activity is part of the International UNEP Mercury Programme, UNEP Mercury Air Transport and Fate Research (UNEP-MFTP) within the framework of the Global Mercury Observation System funded by the EC as part of FP7. Furthermore, the authors gratefully thank Giulio Esposito and A. Capocecera for their support in the use of laboratory instrumentation and A. R. Taddei of the Univeristy of Tuscia (VT-Italy) for providing SEM and TEM micrographs.

Edited by: R. Ebinghaus

Reviewed by: two anonymous referees

\section{References}

Bakir, F., Damluji, S. F., Amin-Zaki, L., Murtadha M, Khalidi, A., al-Rawi, N. Y., Tikriti, S., Dahahir, H. I., Clarkson, T. W., Smith, J. C., and Doherty, R. A.: Methylmercury poisoning in Iraq, Science, 181, 230-241, 1973.

Bui, M. P., Baek, T. J., and Seong, G. H.: Gold nanoparticle aggregation-based highly sensitive DNA detection using atomic force microscopy, Anal. Bioanal. Chem. 388, 1185-1190, 2007. 
Chemnasiri, W. and Hernandez, F. E.: Gold nanorod-based mercury sensor using functionalized glass substrates, Sensor. Actuat. BChem., 173, 322-328, 2012.

Crosby, J.: Mercury Detection with Gold Nanoparticles. Electronic Thesis and Dissertations UC Berkeley, available at: http: //escholarship.org/uc/item/0327r0g6\# (last access: 8 June 2017), 2013.

Dong, Z.-M., Qing, X.-M., and Zhao, G.-C.: Highly Sensitive EQCM Sensor for Mercury Determination by Coupled Stripping Voltammetry, Int. J. Electrochem. Sci., 10, 2602 -2612, 2015.

Drelich, J., White, C. L., and Xu, Z.: Laboratory Tests on Mercury Emission Monitoring with Resonating Gold-coated Silicon Cantilevers, Environ. Sci. Technol., 42, 2072-2078, 2008.

Ferrua, N., Cerutti, S., Salonia, J. A., Olsina, R. A., and Martinez, L. D.: On-line preconcentration and determination of mercury in biological and environmental samples by cold fiber-atomic absorption spectrometry, J. Hazard. Mater., 141, 693-699, 2007.

Ford, R. R. and Pritchard, J.: Work functions of gold and silver films, Surface potentials of mercury and xenon, Trans. Faraday Soc., 67, 216-221, 1971.

Ghaedi, M., Fathi, M. R., Shokrollahi, A., and Shajarat, F.: Highly Selective and Sensitive Preconcentration of Mercury Ion and Determination by Cold Fiber Atomic Absorption Spectroscopy, Anal. Lett., 39, 1171-1185, 2006.

GMOS Database: Land-based Monitoring Sites, http://sdi.iia. cnr.it/geoint/publicpage/GMOS/gmos_historical.zul (last access: 12 June 2017), 2014

Gustin, M. S., Lyman, S. N., Kilner, P., and Prestbo, E.: Development of a passive sampler for gaseous mercury, Atmos. Environ., 45, 5805-5812, 2011.

Gustin, M. S., Huang, J., Miller, M. B., Peterson, C., Jaffe, D. A., Ambrose, J., Finley, B. D., Lyman, S. N., Call, K., Talbot, R., Feddersen, D., Mao, H., and Lindberg, S. E.: Do we understand what the mercury speciation instruments are actually measuring? Results of RAMIX, Environ. Sci. Technol., 47, 7295-7306, 2013

Harner, T., Farrar, N. J., Shoeib, M., Jones, K. C., and Gobas, F.: Characterization of polymer-coated glass as a passive air sampler for persistent organic pollutants, Environ. Sci. Technol., 37, 2486-2493, 2003.

Hedgecock, I., Pirrone, N., Sprovieri, F., and Pesenti, E.: Reactive Gaseous Mercury in the Marine Boundary Layer: Modeling and Experimental Evidence of its Formation in the Mediterranean, Atmos. Environ., 37, 41-49, 2003.

Huang, J., Lyman, S. N., Hartman, J. S., and Gustin, M. S.: A review of passive sampling systems for ambient air mercury measurements, Environ. Sci. Process. Impacts, 16, 374-392, 2014.

James, J. Z., Lucas, D., and Koshland, C. P.: Gold Nanoparticle Films As Sensitive and Reusable Elemental Mercury Sensors, Environ. Sci. Technol., 46, 9557-9562, 2012.

James, J. Z., Lucas, D., and Koshland, C. P.: Elemental mercury fiber interaction with individual gold nanorods, Analyst, 138, 2323-2328, 2013.

Joyner, R. W. and Roberts, M. W.: Auger electron spectroscopy studies of clean polycrystalline gold and of the adsorption of mercury on gold, J. Chem. Soc. Faraday Trans. 1 Phys. Chem. Condens. Phases, 69, 1242-1250, 1973.

Kabir, K., Sabri, Y., Matthews, G., Jones, L., Ippolito, S., and Bhargava, S.: Selective detection of elemental mercury fiber using a surface acoustic wave (SAW) sensor, Analyst, 140, 5508-5517, 2015.

Keebaugh, S., Nam, W. J., and Fonash, S. J.: Manufacturable Higly Responsive Gold Nanowire Mercury Sensors, NSTI-Nanotech, available at: www.nsti.org, 3, 33-36, 2007.

Li, D., McCann, J. T., Gratt, M., and Xia, Y.: Photocatalytic deposition of gold nanoparticles on electrospun nanofibers of titania, Chem. Phys. Lett., 394, 387-391, 2004.

Lyman, S. N., Gustin, M. S., and Prestobo, E. M.: A passive sampler for ambient gaseous oxidized mercury concentrations, Atmos. Environ., 44, 246-252, 2010.

Macagnano, A., Zampetti, E., Perri, V., Bearzotti, A., Sprovieri, F., Pirrone, N., Esposito, G., and De Cesare, F.: Photocatalytically Decorated Au-nanoclusters TiO2 Nanofibers for Elemental Mercury Fiber Detection, Procedia Engineering, 120, 422-426, 2015a.

Macagnano, A., Zampetti, E., and Kny, E.: Electrospinning for High Performance Sensors, Springer International Publishing, 1-329, 2015b.

Macagnano, A., Perri, V., Zampetti, E., Bearzotti, A., Ferretti, A.M., Sprovieri, F., Esposito, G., Pirrone, N., De Cesare, F.: Elemental mercury vapour chemoresistors employing $\mathrm{TiO} 2$ nanofibers photocatalytically decorated with Au-Nanoparticles, Sensor. Actuat. B-Chem., online first, https://doi.org/10.1016/j.snb.2017.03.037, 2017.

McNicholas, T. P., Zhao, K., Yang, C., Hernandez, S. C., Mulchandani, A., Myung, N. V., and Deshusses, M. A.: Sensitive Detection of Elemental Mercury Fiber by Gold-NanoparticleDecorated Carbon Nanotube Sensors, J. Phys. Chem. C, 115, 13927-13931, 2011.

Mohibul Kabir, K. M., Ippolito, S. J., Matthews, G. I., Abd Hamid, S. B., Sabri, Y. M., and Bhargava, S. K.: Determining the Optimum Exposure and Recovery Periods for Efficient Operation of a QCM Based Elemental Mercury Fiber, Sensor Journal of Sensors, 727432-9, https://doi.org/10.1155/2015/727432, 2015.

Morris, T., Kloepper, K., Wilson, S., and Szulczewsk, G.: A Spectroscopic Study of Mercury Fiber Adsorption on Gold Nanoparticle Films, . Colloid Interface Sci., 254, 49-55, 2002.

Müller, K.-H., Wei, G., Raguse, B., and Myers, J.: Threedimensional percolation effect on electrical conductivity in films of metal nanoparticles linked by organic molecules, Phys. Rev. B, 68, 155407, https://doi.org/10.1103/PhysRevB.68.155407, 2003.

Nolan, E. M. and Lippard, S. J.: Tools and tactics for the optical detection of mercuric ion, Chem. Rev., 108, 3443-3480, 2008.

Pacyna, E., Pacyna, J., Sundseth, K., Munthe, J., Kindbom, K., Wilson, S., Steenhuisen, F., and Maxson, P.: Global emission of mercury to the atmosphere from anthropogenic sources in 2005 and projections to 2020, Atmos. Environ., 44, 2487-2499, https://doi.org/10.1016/j.atmosenv.2009.06.009, 2010.

Pirrone, N., Cinnirella, S., Feng, X., Finkelman, R., Friedli, H., Leaner, J., Mason, R., Mukherjee, A., Stracher, G., Streets, D., and Telmer, K.: Global mercury emissions to the atmosphere from anthropogenic and natural sources, Atmos. Chem. Phys, 10, 5951-5964, https://doi.org/10.5194/acp-10-5951-2010, 2010.

Pirrone, N., Aas, W., Cinnirella, S., Ebinghaus, R., Hedgecock, I.M., Pacyna, J., Sprovieri, F., and Sunderland, E. M.: Toward the next generation of air quality monitoring: mercury, Atmos. Environ., 80, 599-611, 2013. 
Plaisance, H., Piechocki-Minguy, A., Gracia-Fouque, S., and Galloo, J. C.: Influence of meteorological factors on the NO2 measurements by passive diffusion tube, Atmos. Environ., 38, 573580, 2004.

Pozo, K., Harner, T., Shoeib, M., Urrutia, R., Barra, R., Parra, O., and Focardi, S.: Passive-sampler derived air concentrations of persistent organic pollutants on a north-south transect in Chile, Environ. Sci. Technol., 38, 6529-6537, 2004.

Raffa, V., Mazzolai, B., Mattoli, V., Mondini, A., and Dario, P.: Model validation of a mercury sensor, based on the resistivity variation of a thin gold film, Sensors Actuat. B-Chem., 114, 513$521,2006$.

Ratner, N. and Mandler, D.: Electrochemical Detection of Low Concentrations of Mercury in Water Using Gold Nanoparticles, Anal. Chem., 87, 5148-5155, 2015.

Sabri, Y. M., Ippolito, S. J., Tardio, J., Atanacio, A. J., Sood, D. K., and Bhargava, S. K.: Mercury diffusion in gold and silver thin film electrodes on quartz crystal microbalance sensors, Sensor. Actuat. B-Chem., 137, 246-252, 2009.

Sabri, Y. M., Ippolito, S. J., O’Mullane, A. P., Tardio, J., Bansal, V., and Bhargava S. K.: Creating gold nanoprisms directly on quartz crystal microbalance electrodes for mercury fiber sensing, Nanotechnology, 22, 305501, https://doi.org/10.1088/09574484/22/30/305501, 2011.

Sánchez-Rodas, D., Corns, W. T., Chen, B., and Stockwell, P. B.: Atomic Fluorescence Spectrometry: a suitable detection technique in speciation studies for arsenic, selenium, antimony and mercury, J. Anal. At. Spectrom., 25, 933-946, 2010.

Sderstrm, H. S. and Bergqvist, P. A.: Passive air sampling using semipermeable membrane devices at different wind-speeds in situ calibrated by performance reference compounds, Environ. Sci. Technol., 38, 4828-4834, 2004.

Sprovieri, F., Pirrone, N., Bencardino, M., D'Amore, F., Carbone, F., Cinnirella, S., Mannarino, V., Landis, M., Ebinghaus, R., Weigelt, A., Brunke, E.-G., Labuschagne, C., Martin, L., Munthe, J., Wängberg, I., Artaxo, P., Morais, F., Barbosa, H. D. M. J., Brito, J., Cairns, W., Barbante, C., Diéguez, M. D. C., Garcia, P. E., Dommergue, A., Angot, H., Magand, O., Skov, H., Horvat, M., Kotnik, J., Read, K. A., Neves, L. M., Gawlik, B. M., Sena, F., Mashyanov, N., Obolkin, V., Wip, D., Feng, X. B., Zhang, H., Fu, X., Ramachandran, R., Cossa, D., Knoery, J., Marusczak, N., Nerentorp, M., and Norstrom, C.: Atmospheric mercury concentrations observed at groundbased monitoring sites globally distributed in the framework of the GMOS network, Atmos. Chem. Phys., 16, 11915-11935, https://doi.org/10.5194/acp-16-11915-2016, 2016.
Sprovieri, F., Pirrone, N., Bencardino, M., D'Amore, F., Angot, H., Barbante, C., Brunke, E.-G., Arcega-Cabrera, F., Cairns, W., Comero, S., Diéguez, M. D. C., Dommergue, A., Ebinghaus, R., Feng, X. B., Fu, X., Garcia, P. E., Gawlik, B. M., Hageström, U., Hansson, K., Horvat, M., Kotnik, J., Labuschagne, C., Magand, O., Martin, L., Mashyanov, N., Mkololo, T., Munthe, J., Obolkin, V., Ramirez Islas, M., Sena, F., Somerset, V., Spandow, P., Vardè, M., Walters, C., Wängberg, I., Weigelt, A., Yang, X., and Zhang, H.: Five-year records of mercury wet deposition flux at GMOS sites in the Northern and Southern hemispheres, Atmos. Chem. Phys., 17, 2689-2708, https://doi.org/10.5194/acp17-2689-2017, 2017.

Sun, Y. and Xia, Y.: Gold and silver nanoparticles: A class of chromophores with colors tunable in the range from 400 to $750 \mathrm{~nm}$, Analyst, 128, 686-691, 2003.

Yuan, Y., Zhao, Y., Li, H., Li, Y., Gao, X., Zheng, C., and Zhang, J.: Electrospun metal oxide-TiO2 nanofibers for elemental mercury removal from flue gas, J. Hazard. Mater., 227-228, 427435, 2012.

Zampetti, E., Pantalei, S., Muzyczuk, A., Bearzotti, A., De Cesare, F., Spinella, C., and Macagnano, A.: A high sensitive $\mathrm{NO}_{2}$ gas sensor based on PEDOT-PSS/TiO 2 nanofibers, Sensor. Actuat. B-Chem., 176, 390-398, 2013.

Zhang, W., Tong, Y. D., Hu, D., Ou, L. B., and Wang, X. J.: Characterization of atmospheric mercury concentrations along an urban-rural gradient using a newly developed passive sampler, Atmos. Environ., 47, 26-32, 2012. 